University of Louisville

ThinkIR: The University of Louisville's Institutional Repository

Electronic Theses and Dissertations

$12-2009$

\title{
A Ferrari engine with bicycle brakes : mothers' perceptions of family communication patterns when having an ADHD child.
}

Anita Hoag 1967-

University of Louisville

Follow this and additional works at: https://ir.library.louisville.edu/etd

\section{Recommended Citation}

Hoag, Anita 1967-, "A Ferrari engine with bicycle brakes : mothers' perceptions of family communication patterns when having an ADHD child." (2009). Electronic Theses and Dissertations. Paper 623.

https://doi.org/10.18297/etd/623

This Master's Thesis is brought to you for free and open access by ThinkIR: The University of Louisville's Institutional Repository. It has been accepted for inclusion in Electronic Theses and Dissertations by an authorized administrator of ThinkIR: The University of Louisville's Institutional Repository. This title appears here courtesy of the author, who has retained all other copyrights. For more information, please contact thinkir@louisville.edu. 
A FERRARI ENGINE WITH BICYCLE BRAKES: MOTHERS' PERCEPTIONS OF FAMILY COMMUNICATION PATTERNS WHEN HAVING AN ADHD CHILD

\author{
By \\ Anita Hoag \\ B.S., Northeastern University, 1990 \\ A Thesis \\ Submitted to the Faculty of the \\ Graduate School of the University of Louisville \\ In Partial Fulfillment of the Requirements \\ For the Degree of
}

Master of Arts

Department of Communication

University of Louisville

Louisville, Kentucky

December 2009 



\section{A FERRARI ENGINE WITH BICYCLE BRAKES: MOTHERS' PERCEPTIONS OF FAMILY COMMUNICATION PATTERNS WHEN HAVING AN ADHD CHILD \\ By \\ Anita Hoag \\ B.S., Northeastern University, 1990}

A Thesis Approved on

November 30, 2009

by the following Thesis Committee

Kandi L. Walker, Ph.D.

Joy L. Hart, Ph.D.

S. Lee Ridner, Ph.D. 


\section{DEDICATION}

This thesis is dedicated to all children who have ADHD. May you experience tolerance, understanding, and patience from whomever you encounter. 


\section{ACKNOWLEDGEMENTS}

I would like to thank my advisor, Dr. Kandi Walker for believing in my topic and for spending countless hours guiding me through the thesis process. This project turned out much better than it ever could have been because of her help. I would also like to thank my other committee members, Dr. Joy Hart and Dr. S. Lee Ridner for supporting my topic and for always having to read my edits at the last possible minute. Thank you to all of the mothers who graciously gave me their time and shared their stories about their children and families. Without their participation, this project would not exist. Thank you to my husband, Mike who came home from work early twice a week for the past year and a half so that I could get to class on time. You were always there when I needed more help with the kids, and you were a great sounding board. After all these years, you still rock my world! Thank you to my children, Andrew and Katharine who are two of my biggest cheerleaders. They think it is really cool to have a mother in graduate school. I would also like to thank Spumoni, our beautiful Wheaten Terrier for listening to my ideas and for keeping my feet warm while I was writing. Finally, thank you to my friends Robyn and Jeanne - it takes a village. 


\begin{abstract}
A FERRARI ENGINE WITH BICYCLE BRAKES: MOTHERS' PERCEPTIONS OF FAMILY COMMUNICATION PATTERNS WHEN HAVING AN ADHD CHILD

Anita Hoag

December 17, 2009
\end{abstract}

The purpose of this study was to explore how mothers with an ADHD child living in the household perceive and manage family communication. In-depth interviews were conducted amongst nine married mothers who have an ADHD child. Three themes emerged from the interview data: relational management, time management, and internal and external support. Mothers communicate with their ADHD child differently than their non-ADHD children and must also manage communication about the ADHD diagnosis. Mothers are not always open about their child's ADHD with non-family members as they are afraid of the stigma that is attached to the condition. Mothers recognize that they spend considerable time on their child's ADHD issues and their time given to others in the family may be compromised. It is also necessary for mothers to receive emotional and pragmatic support from the family, friends, and professionals. 
TABLE OF CONTENTS

PAGE

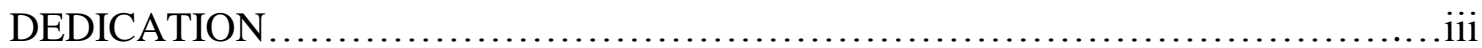

ACKNOWLEDGEMENTS ........................................................

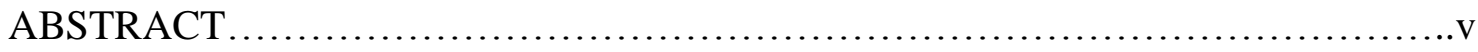

INTRODUCTION/LITERATURE REVIEW .....................................

Parental Communication and ADHD .......................................

Mother-Child Communication.............................................11

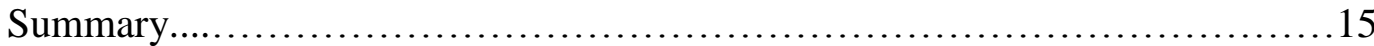

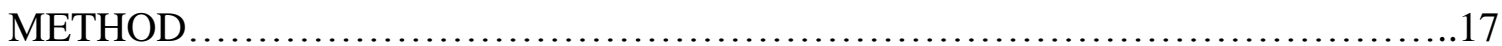

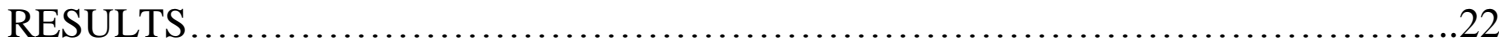

Relational Management.................................................... 22

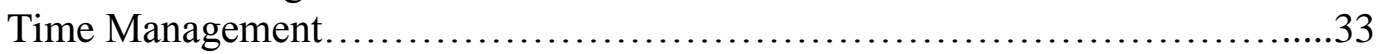

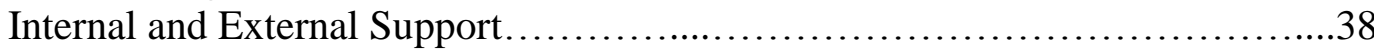

Summary of Results.................................................... 47

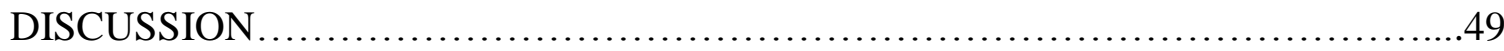

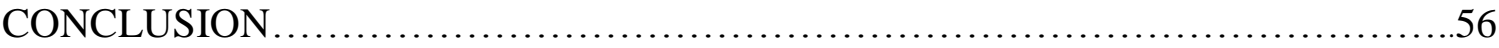

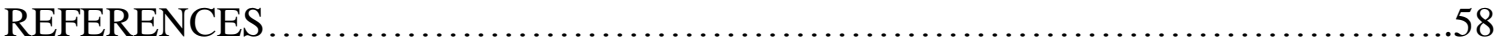

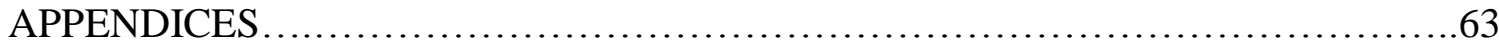

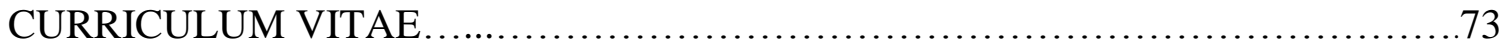




\section{INTRODUCTION/LITERATURE REVIEW}

According to the American Psychiatric Association (2000) "Attention-

Deficit/Hyperactivity Disorder (ADHD) is a persistent pattern of inattention and/or hyperactivity-impulsivity" (p. 85). In order for a diagnosis to be made, it must be shown that the ongoing ADHD symptoms of inattentive and/or impulsive/hyperactive behavior significantly impair functioning in two or more settings (e.g. home, school, or work) (American Psychiatric Association, 2000; See Appendix A for diagnostic criteria as published in the DSM-IV-TR). Studies have demonstrated that those who are affected by ADHD have a family history of ADHD or other types of disorders such as Mood and Anxiety Disorder, Learning Disorders, Substance-Related Disorders, and Antisocial Personality Disorder (American Psychiatric Association, 2000).

ADHD occurs more frequently in males than females. With the reasons why remaining unclear, one explanation by Armstrong (1995), author of The Myth of the A.D.D. Child is that "some boys may be at risk to be identified as hyperactive or ADD simply because their gender-appropriate activities clash with the expectations of a highly verbal, highly schedule-oriented, and usually female-dominated classroom environment" (pp. 31-32). A study conducted by McGuinness (1990) states boys ages 3-5 can be characterized as "highly interruptible and less able than girls to settle for any length of time to a task" (p. 322). McGuinness observed preschool children (38 boys and 35 girls; ages 3-5) during free play sessions. The time spent on any given activity was longer for girls than for boys (12 minutes versus 8) and boys interrupted their play time more often 
than girls. In addition, boys had greater interest in objects, while girls were more interested in people (McGuinness, 1990). However, it is when the child reaches schoolage and still cannot maintain focus, stay seated, or remain on task that there is reason for concern.

Current estimates report that 3-7\% of school-age children have ADHD (2000). Children with ADHD are typically careless and messy with their schoolwork (they pay little attention to details), appear not to listen when being spoken to, and have trouble organizing and completing tasks (American Psychiatric Association, 2000). They can also be forgetful, easily distracted, and fidgety (e.g., not able to remain seated during meal times) (American Psychiatric Association, 2000). Other implications for those who have this disorder are that academic and vocational success may not be present even though they may be above-average or gifted in terms of their intellectual development (Weinberg, 1999).

There are also many behavioral issues that an ADHD child experiences, with the main issue being impulsiveness. The impulsiveness of the child is perceived as the child being impatient - interrupting people and having trouble waiting one's turn, grabbing items out of other people's hands, or not being aware of other people's personal space. They may also experience outbursts, frustration, stubbornness, problems with friendships, and poor self-esteem. In terms of family relationships, according to the $D S M-I V-T R$, ADHD children are often "characterized by resentment and antagonism, especially because variability in the individual's symptomatic status often leads others to believe that all the troublesome behavior is willful" (American Psychiatric Association, 2000, p. 
88). The DSM-IV-TR states that as a result discord and negative parent-child interactions are present within the family.

Unfortunately, there is also a stigma attached to those who have ADHD. This type of stigma, using a description by sociologist Erving Goffman (1963), is discreditable as the "differentness is not immediately apparent" (p. 42). The fact that the condition does not become immediately apparent to people is especially true for those who do not have a severe case of this disorder. It can also be difficult for others to recognize the disorder if they are not familiar with the symptoms. Because the discreditable stigma is easy to hide, one of the issues concerning this type of stigma is "whether to reveal or conceal. The major problem for the discreditable person is information control, or the management of undisclosed discrediting information about self” (Montgomery \& Baxter, 1998, p.84). This problem can have an effect on how parents talk about their child's condition within and outside of the family.

In addition, there is societal doubt that goes along with this disorder, stemming from controversy about whether or not ADHD is over diagnosed and if the medications for this condition are overprescribed. The combination of these facts has helped to lay the ground work for a plethora of research on the subject. Some of this research focuses on the relationship between ADHD and eating disorders (Dukarm, 2005), substance abuse, (Roberts, Roberts, \& Chan, 2009), learning disabilities (Crawford, 2007; McNamara, Vervaeke, \& Willoughby, 2008; Padolsky, 2008), and self-esteem (Ferrari, 2000; Edbom, Granlund, Lichtenstein, \& Larsson, 2008; Ek, Westerland, Holmberg, \& Fernell, 2008). 
The relationships between ADHD and the above mentioned conditions are important to investigate because, according to the National Institute of Mental Health (2009), they tend to coexist with ADHD. For example, "a child in preschool with a learning disability may have difficulty understanding certain sounds or words or have problems expressing himself or herself in words. A school-aged child may struggle with reading, spelling, writing, and math" (National Institute of Mental Health, 2009). However, it is also important to research how a child's ADHD symptoms are being managed at home.

When parents communicate with their children who have ADHD, their style must be altered to accommodate their children's needs (Armstrong, 1995). For example, a child with ADHD needs more praise, rewards, and forgiveness versus a child without (Armstrong, 1995). In addition, parents must be able to state expectations in a concise manner, rather than use long sentences in order to retain their child's attention (Armstrong, 1995). Because it is difficult for ADHD children to process longer, complex sentences or explanations, confusion and misunderstandings often ensue between the child, parents, and other family members (American Psychiatric Association, 2000). Therefore, it is important to begin by examining the way families with ADHD children living in the same household communicate with each other as well as understand how they perceive family communication.

\section{Parental Communication and ADHD}

In order to examine communication in these types of households, it is helpful to define what communication means. In essence, "communication is the process of 
meaning-making” (Turner \& West, 2006, p. 16). These relationships especially between the parent and child are considered to be "critical influences on children's identities" (Wood, 2007, p. 334). At the same time, parents must be able to find the right balance of being authoritative while also teaching their children how to make responsible decisions on their own. In the ADHD household, it is important to understand the communication patterns that are present, and how different approaches to parenting affect communication behaviors and family relationships.

There have been many studies about family communication patterns, especially about parent-child relationships. For example, Fitzpatrick, Leutwiler, Kremar, and Marshall (1996) examined family communication environments of school-aged children in grades 1, 4, 6, and 7 and how those environments affected their social behavior. The children were shown "talking picture books" and cartoon pictures that depicted different families and different types of family communication.

Based on this information, the children identified their own families in terms of the type of communication that was present in their household (i.e., pluralistic, consensual, protective, or laissez-faire). Children completed the revised Peabody Picture Vocabulary Test which measures vocabulary and verbal ability. In addition, teachers rated each child's social self-restraint ability (meaning how well they could control themselves) and how often they became socially withdrawn. The results suggested that "family communication environments may be differentially beneficial for boys and girls at particular points of development" (Fitzpatrick, et al., 1996, p. 379). In other words, boys and girls develop at different rates so what may work for a ten-year-old boy may not 
be effective for a girl of the same age. For example, they found that "fourth-grade girls were significantly more socially withdrawn than either fourth- or sixth-grade boys, and first-grade girls were significantly more withdrawn than fourth-grade boys" (Fitzpatrick, Leutwiler, Krcmar, \& Marshall, 1996, p. 394). These findings beg the question of whether or not certain communication environments would be more beneficial for ADHD children. In other words, what family communication strategies and patterns work for ADHD children? Also, do different family communication strategies and patterns work differently for ADHD children and at what stages of development?

Smith and Barrett (2002) asked whether or not parental training had a positive affect on school-aged girls in terms of their symptoms of hyperactivity and inattentiveness. Mothers of the children participated in the Defiant Children program, a ten-week program that teaches parents "cognitive-behavioral parenting methods for dealing with children who have compliance difficulties" (Smith \& Barrett, 2002, p. 25). The participating mothers and their daughters were videotaped while interacting in their home before the first session and after sessions five and nine. Families were videotaped twice for twenty minutes in each session and given a 10-minute break in between. One session was an unstructured activity of their choosing, and the other was a specific task chosen by the researcher.

The observations were coded based on five criteria: off-task (child's inattentiveness), hand fidgeting, body fidgeting, sounds (vocal sounds made by the child), and time to compliance (how long it took the child to comply with parental direction). Aside from the parental training and observations, the mother also completed the Child 
Behavior Checklist. This questionnaire asks parents to rate their child's behavior on more than 100 different problem areas. The results of this study suggest that these training programs may focus more on overt behaviors at the sacrifice of other symptoms. If the parents intervened with some of the behaviors it may have been at the expense of being able to manage other symptoms. For example, body fidgeting decreased but it was at the expense of off-task behavior. The question becomes whether or not the parents have to live with certain negative behaviors if they persuade their ADHD child to comply with other more positive behaviors.

Similarly, Weinberg (1999) also examined parents who had children with ADHD who participated in a group parent training program. Hoping to improve a child's behavior, Weinberg had 34 parents participate in a 6-week parent training program to assist them in learning about ADHD and behavior management. The participants' children ranged in age from 4-12 (20 boys and 5 girls). Parents attended six 90-minute group sessions on a weekly basis.

Most of the time was spent on behavior management techniques, but they were also given an overview of "ADHD, co-morbidity, medications, behavior management techniques, and school-related issues" (Weinberg, 1999, p. 909). Parents completed preand postparticipation questionnaires regarding knowledge (ADHD, medications, and behavior management skills), stress levels ranging from very little to very severe, and their home situation (problem areas rated by severity on a scale from 1-9). Finally, they were asked to complete an evaluation of the program which asked them about parental expectations, relevance of the material, method of presentation, and the presenter. 
The result was that parental knowledge about ADHD and behavioral management increased while their stress levels modestly decreased. However, "parents did not observe improvements in the number of behavior problems and their severity in their children at the end of the 6-week program" (Weinberg, 1999, pp. 909-910). The results of this study suggest parents' ability to cope and understand ADHD issues improved after the educational program but the children's ADHD issues (i.e., the child's behavioral issues) did not change. It seems it would have been helpful if the parental educational program also focused on family communication. More specifically, the parents would have benefited more if they were taught how to manage the child's ADHD behavioral issues. Dealing with an ADHD child's behavior is an issue that families confront daily. Another issue families face is how behavior and hyperactivity problems manifest themselves depending on the family structure.

Kerr and Michalski (2007) longitudinally examined family structure in relation to their children's hyperactivity problems. The authors used 1994-2000 data from the Canadian National Longitudinal Survey of Children and Youth that measured child development and well-being. They wanted to find out whether there is a link between family structure and children's developmental outcomes. They found that those who were a part of an intact family had less hyperactivity and attention problems versus those who were a part of another family configuration. They also found that as children moved through their elementary school years, there was a decrease in hyperactivity-inattention. There are obviously differences in family communication patterns in those families that are intact versus those that are not. Another question to consider is whether or not being a part of an intact family is even more beneficial to the ADHD child. 
Tripp, Schaughency, Langlands, and Mouat (2007) were concerned with the ways families interacted when they had a child with ADHD and a child without ADHD. They studied 51 children who were diagnosed with ADHD and 32 children who did not have any behavioral difficulties (non problem children). Twenty-six of the children with ADHD also had a disruptive behavior disorder other than ADHD. The ages of all children ranged from 5-12. It should be noted that the children diagnosed with ADHD were not taking medication or were suspending its usage for the study. All children were given a "comprehensive diagnostic assessment including standardized semi-structured parent, teacher, and child interviews" (Tripp, et al., 2007, p. 388). Also included were parent and teacher rating scales and an assessment of the child's cognitive functioning. In addition, the parents were required to complete demographic questionnaires and "self-report measures of depressive symptomology (Beck Depression Inventory) and parenting stress" (Tripp et al., 2007). In order to examine parent-child interaction, the families were videotaped for 40 minutes, with the first 20 minutes focused on two problem-solving exercises. The first was a discussion about a child-generated problem and the second was a parent-generated problem. Each discussion lasted until they could find a solution or until 10 minutes had passed. The final 20 minutes were spent playing the board game "Trouble" which was chosen because it is easy for children in this age range to understand the game.

The researchers found that during the problem solving tasks interactions between the families without ADHD were warmer, more engaged, and with more effective communication. They also found that during game playing there was a trend toward lower levels of engagement with the ADHD group. This study suggests that the manner 
in which families communicate and their overall dynamic is affected by whether or not a particular family has an ADHD child living in the same household. Another area that is of importance to ADHD families is finding alternative strategies that would help in improving the ADHD child's attention span and ability to focus.

Zentall (2005) focused on strategies to improve selective and sustained attention for children who have ADHD. She discussed the use of medication and behavioral consequences and self-monitoring techniques. She also looked at educational interventions that actually improved the attention of these children. She found that "educational interventions that involve increasing antecedent (task and setting) stimulus conditions have been demonstrated to normalize attention, and some actually improved the attentional performance of children with ADHD beyond that of their peers" (Zentall, 2005, p. 821). An interesting observation was that if an ADHD child behaves in an inappropriate way, responding loudly and emotionally to children may initially stop the behavior. However, this type of long-term response can actually increase subsequent negative behavior. Learning how to better communicate with the ADHD child as well as learning behavioral modification techniques is important to help improve the overall family dynamic. In addition, it is also important to examine the mother-father dyad in relation to how they view their ADHD child's behavior.

Chen, Seipp, and Johnston (2007) compared the beliefs held by fathers and mothers about their ADHD children. Participants in this study were mother-father pairs of 19 girls and 17 boys with ADHD, ranging in age from 5 to 13 years old. Parents were recruited as part of a larger study that examined their attributions and knowledge of ADHD. Parents were asked about their child's level of impairment, and were given the 
Written Analogue Questionnaire which had 10 written scenarios that described child behavior. Five of the scenarios described impulsive symptoms and the remaining five described inattentive symptoms.

Based on these scenarios, parents were asked to rate the cause of the child's behavior. The causal locus of behavior, globality of behavior, stability of the behavior, and the child's control over the behavior were rated. In addition, parents were asked to rate their reactions to each scenario. In general, mothers had less negative reactions to the child's ADHD symptoms and attributed the inattentive and impulsive symptoms as part of a biologically-based disorder. On the other hand, fathers endorsed less evidence-based beliefs such as ADHD is present because of a lack of effort on the child's part. Mothers and fathers also differed in their beliefs concerning treatment where mothers believed more in behavioral management, and fathers believed in more psychological treatments. This study demonstrates that mothers and fathers have differing viewpoints when it comes to understanding and managing their child's ADHD symptoms. It is important to understand why such differences in opinion could occur. One way to understand these differences is to examine the role of the mother and her relationship with her children.

\section{Mother-Child Communication}

It is difficult to contradict the significance of the mother's role in terms of taking care of her children, protecting them, and providing emotional support. Julia Wood's (2007) book Interpersonal Communication: Everyday Encounters discusses that in

general, mothers "communicate more with children than fathers and use talk to give information, advice, encouragement, and support to children" (p. 335). In addition, they 
are the ones who usually teach their children how to relate to others socially (including being sensitive), as well as to manage their emotions (Wood, 2007, p. 335).

In terms of research that has explored the mother-child relationship, Gregory and Rimm-Kaufman (2008) conducted a longitudinal study that examined mother-child interactions when the child was in kindergarten to predict high school academic success. They began with a sample of 342 children who were entering kindergarten in a Southeast school district. Follow-up data extracted from school records where there were 142 children left in the school district by high school graduation was analyzed. Mothers and their kindergartners were observed interacting, and the mothers were rated based on maternal dimensions (i.e., supportive presence, quality of instruction, and respect for the child's autonomy). Children were also rated with five child dimensions (i.e., affection, reliance on the adult for help, negative affect, task orientation, and enthusiasm). They found that "positive mother-child interactions in kindergarten were associated with an increased likelihood of high school graduation and, for some students, a higher gradepoint average by $12^{\text {th }}$ grade" (Gregory \& Rimm-Kaufman, 2008, p. 508-509). This increased likelihood of high school graduation was true regardless of race/ethnicity, socioeconomic status, gender, or intelligence quotient. "Positive mother-child interactions in kindergarten were linked with higher grades 12 years later for children at risk for school failure" (Gregory \& Rimm-Kaufman, 2008, p. 509). These findings suggest that it is even more important for positive mother-child interactions to take place between the mother and the ADHD child as those children are at higher risk for not experiencing academic success. 
In terms of studying family behavior and how it affects mothers, Kendall, Leo, Perrin, and Hatton (2005) examined child behavior, maternal distress and family conflict. Using a community sample of families with children who have ADHD, they tested child behavior problems, maternal distress, and family conflict. Their research showed that mothers in ADHD families are of critical importance as the distress felt by the mothers helps to mediate the relationship between behavioral problems on the child's part and family conflict. They also concluded that mothers of ADHD children need additional emotional support. This conclusion raises questions in relation to how mothers actually speak to their partners as well as their ADHD children versus their non-ADHD children.

More specific studies that focus on the mother and ADHD child relationships have covered mothers' reports of parenting, attributions for their child's behavior, and overall beliefs concerning their children. For example, the results from a study conducted by Johnston, Scoular, and Ohan (2004), which looked at mothers' reports of parenting an ADHD child, suggested that "in families of children with ADHD, over-reactivity in parenting is an important dimension related to the presence of impulsive or oppositional problems in either child or mother" (p. 55). In this study, 42 mothers of 7 to 12 -year-old boys with ADHD completed two self-reports that measured parenting practices which were compared to observations of parenting behavior. "The results of this study suggest that reports of parenting in mothers of children with ADHD symptoms are not unduly influenced by impression management, and are related to both maternal and child functioning” (Johnston et al., 2004, p. 46).

Gerdes and Hoza (2006) studied maternal attributions, affect, and parenting in mothers of ADHD children and unaffected children. They predicted that mothers of 
ADHD children would view negative child behaviors as less controllable and intentional. In addition, they predicted those parents would report "more negative affect and power assertive parenting in response to these behaviors versus mothers of non-ADHD children" (Gerdes \& Hoza, 2006, p. 354). In terms of positive behaviors, they predicted that mothers of ADHD children would report less positive affect and would not be as likely as mothers of non-ADHD children to report the use of positive parenting.

Participants included 23 children aged 7-12 (19 boys, 4 girls) with ADHD and their mothers compared to 29 children aged 7-12 (21 boys, 8 girls) without ADHD and their mothers. Children were videotaped while they were engaged in several tasks with a research assistant and an interaction task with their own mothers. Tasks with the research assistant included cleaning up a mess of papers, allowing the research assistant to take the first turn in playing with a Sony Playstation, and completing a symbol coding task that the authors considered boring. In the mother-child interaction task, the child, who was alone with the research assistant was instructed to play a game on the Playstation. When the mother entered the room, she instructed the child to stop playing and either complete a homework or clean-up task.

Aside from the mother/child interaction task, the mothers were given written vignettes which described four target behaviors: noncompliance, inattentive-impulsive behavior, compliance, and pro-social behavior. The mothers were asked to imagine that their children were the ones who were described in the written vignettes. Mothers were also shown video clips of a 9-year-old confederate child acting out two of the four target behaviors, and asked to also imagine that it was their child acting out those behaviors. 
Results demonstrated that the mothers of ADHD children viewed noncompliance as being less controllable than the mothers of the non-ADHD children.

In other words, they believed that their ADHD children were not behaving in a negative way on purpose. Mothers of the ADHD children also viewed inattentiveimpulsive behavior as less controllable and intentional versus the mothers of the nonADHD children. In terms of compliance and pro-social behavior, mothers of the ADHD children viewed those behaviors as being less controllable and global/stable versus the mothers of the non-ADHD children. However, the mothers of the ADHD children would respond to those behaviors with more positive parenting versus the other mothers.

\section{Summary}

Research has made a contribution to understanding family communication patterns, ADHD children, and the mother-child relationship. The study conducted by Fitzpatrick et al. (1996) demonstrated that family communication patterns can affect perceptions of parent-child satisfaction, how beneficial patterns are based on a child's stage of development, and the levels of listening anxiety and intellectual inflexibility. Smith and Barrett's (1996) and Weinberg's (1999) studies demonstrated the importance of parental training but that even though parents' stress levels improved, either certain child behaviors improved at the expense of others or they did not improve at all. In addition, Kendall et al. (2005) showed that maternal distress played a role in mediating behavioral problems and family conflict while Tripp et al. (2007) illustrated more warmth and communication effectiveness for families without ADHD children versus those with ADHD. 
The studies that revolved around mothers and parenting of ADHD children provided clues that parenting communication styles and patterns, as well as whether or not there are positive interactions between the parent and affected child help to determine the child's long-term success. The mother of an ADHD child must use a positive parenting approach and needs to understand her child's condition so she can effectively parent her child. As research shows, mothers often play an instrumental role for children and families. They are often giving information, advice, encouragement, support, and helping children socialize and manage their emotions. Therefore, this study seeks to better understand family communication strategies associated with having a child diagnosed with ADHD. Specifically, I will examine mothers' perception of family communication as follows: how they experience and communicate with an ADHD child, how other family members communicate with that child, and how mothers manage the communication about their ADHD child with those who are outside the family. The purpose of this study is to better understand how mothers with an ADHD child experience, manage, and perceive family communication. With that in mind, the following overarching research questions were posed:

RQ1: How do mothers perceive family communication in relation to having a child diagnosed with ADHD?

RQ2: How do mothers communicatively experience and manage having both an ADHD child and a non-ADHD child living in the same household? RQ3: How do mothers discuss their ADHD child with family and non-family members? 


\section{METHOD}

In order to answer each of the research questions, an exploratory qualitative research design study using in-depth interviews and thematic analysis was employed. This design allowed themes of mothers' perceptions of family communication surrounding having a child diagnosed with ADHD to emerge. Below I detail the study sample, data collection, and data analysis.

\section{Study Sample}

Recruitment. After approval from the University of Louisville's Human Subjects Protection Program, I employed a convenience sampling method to find potential interviewees. I contacted friends and other contacts from my interpersonal networks requesting their participation or help in identifying potential mothers known to have a child(ren) diagnosed with ADHD.

Selection. Mothers were asked to participate in this study if they met the study's three qualifications: Mothers needed to have a child diagnosed with ADHD, the child must be living in the same household as the mother, and the mothers had to be a part of a two parent household. If a mother met the study qualifications she was invited to participate. If she agreed to volunteer for the study, a time and place for the interview were set.

Description. The original sample size consisted of 11 participants; however, data from two of the participants was not included in the final analysis. Two families without a two-parent household deemed to be outliers in the data so they were not included in the 
final data analysis. Nine mothers, all Caucasian, remained in the study, with their ages ranging from 35-48 ( $M=42.6$ years). Most of the mothers work at least 15 hours per week ( $M=24.4$ hours per week). In terms of education, three of the mothers have a Bachelor's degree, five have a Master's, and one is a medical doctor. All of the participants were higher socio-economic status with household incomes greater than $\$ 150,000$. All the participants had children living in the household (ranging from 1-3 total children, $M=2.3$ children). The ages of the children diagnosed with ADHD range from 6-13, $(M=9.6$ years $)$. The children's ages when diagnosed with ADHD range from 4-8 years $(M=5.4)$. Of the nine children diagnosed with ADHD, eight of them are boys and one is a girl. All of the children have other siblings in the household except for one. The ages of the siblings range from 18 months to 19 years $(M=9.7$ years; See Tables 1 and 2 for Demographic Breakdown and Summary). It is important to note that one of the ADHD children has also been diagnosed with Bipolar Disorder and another child has also been diagnosed with Asperger's Disorder (both boys). Those interviews did not focus on the other diagnoses but I was made aware of the coexisting conditions before the interviews took place.

Data Collection. I obtained informed consent from the women before each interview. Additionally, I debriefed the participants at the end of each interview to ensure that any remaining questions were answered. The interviews took place in the homes $(n=7)$ or offices $(n=4)$ of the participants. Each interview lasted between 46 and 90 minutes $(M=57.2$ minutes $)$. The interview time did not include study description, answering questions, and explaining and signing the consent form. 
Interview Procedures. Interviews were semi-structured and consisted of openended questions. They were conducted in-person and audio recorded. The open-ended questions allowed for flexibility in terms of being able to incorporate probes in order to gather more in-depth information. In addition to open-ended questions, demographic information was collected from each of the participants. Detailed field notes were taken during each interview. Immediately after each interview, I documented my impressions about the interview. I also reviewed my notes taken during the interview to correct and clarify points.

Interview Guide. The interview guide consists of 23 questions that were designed to examine what mothers encountered before, during, and after their child was diagnosed with ADHD (See Appendix B). In addition, the mothers were asked to talk about how they manage communication within and outside of the household about their ADHD child. Routines and discipline strategies were discussed in terms of both their affected and unaffected child. How the mother and child deal with problem solving and examples of how the child gets into trouble were also covered. The questions were asked using the funnel-based approach, beginning with the participant being asked about what it is like to be a mom and moving to more specific questions regarding the diagnosis, communication, and challenges.

The interview guide contains questions such as: "Tell me about being a mom.”, "Describe some of the warning signs that you encountered where you knew something was different with your child.", "Tell me about life after the diagnosis.", "Describe how mothering your child has changed since receiving the diagnosis.", "In your household, 
describe a typical day.", "Describe some of the discipline strategies that you use with your other children.", "Tell me about a time when your child had a problem that was solved.", "What kind of emotional support do you receive from your partner or spouse?", "What are some of the biggest challenges that you face with your child?", "What are some of the biggest challenges that you see your child facing because of the ADHD?", and "Describe some of the communication strategies that you have found to work in terms of talking with your child."

Data Analysis

All interviews were transcribed which resulted in 13.5 hours of interviews which yielded 158 single-spaced pages of transcription. Saturation was declared after seven interviews, as no new themes were emerging. At that point, four more interviews were conducted to account for the outliers and to ensure that saturation was met. The final analysis consisted of 11 hours of interviews with 130 single-spaced pages of transcriptions.

Once the interviews were transcribed, they were uploaded to QDA Miner, a qualitative data analysis software package. Similar to the constant comparative technique (see Corbin \& Strauss, 2008), having the transcriptions in the QDA Miner program allowed me to follow a multi-phase analysis process. I coded the data for preliminary themes by looking for commonalities across all interviews employing Owen's (1984) standard for identifying themes: recurrence, repetition, and forcefulness. I then created codes and categories based on the interviewees' responses.

I continued to analyze the data and review my codes and categories making adjustments to add, consolidate, and/or eliminate codes and categories to allow for a 
more accurate analysis. It was at this point in the process that the categories were compared and contrasted in order to look for emerging themes. I continued to revise my codes and categories until I had themes capable of indexing all my data. The themes that emerged provide insight to the three research questions that were posed. 


\section{RESULTS}

From my interviews, three overarching themes emerged: Relational Management, Time Management, and Internal and External Support. Below I examine the emergent themes and provide examples from the participants. Table 3 summarizes my findings.

\section{Relational Management}

The first emergent theme in this study was Relational Management. This theme was conceptualized as mothers' perceptions that they are the managers of the relationships within the household (i.e., child diagnosed with ADHD, other children, and spouse) and they are the managers of external relationships and communication (i.e., they are responsible for how and when the child's ADHD diagnosis is revealed and for managing interpersonal complexities that arise due to issues surrounding ADHD). The participants in this study perceived their role as playing relationship managers because (as one participant stated) "having a child with ADHD changes the entire family dynamic and changes how you talk with others about your children." In short, the mothers perceived they had a multi-faceted role of trying to maintain decorum inside the home

(i.e., "keeping everyone relatively happy") and trying to manage outsider's perceptions of their families (e.g., "defending" the family if needed).

The mothers of this study repeatedly talked about managing the relationships within the home. One of the significant relationships that they manage was the relationship with their ADHD child. Mothers often reported that communicating with their ADHD child was more complex than other children's communication, stating that 
simple requests and directions could often go awry. Capturing this sentiment best, one mother (M007) stated that communicating with her "ADHD child is more stressful because I know that what can start out as an ordinary conversation can quickly escalate into a full blown negotiation which then leads to arguments with voices raised and foul language" used by both parties. "He will be in my face and it's escalating." Another mother (M003) told a story about a confrontation with her son that escalated to the point that she screamed so loudly that she lost her voice for three days. When asked what the argument was about, she could not even remember. She did remember that it was a normal request that she thought would be "no big deal."

Often with nonverbal that would suggest regret, the mothers of the study talked about perceiving their ADHD child in a "not so positive light" (M003). The mothers reported that because the ADHD child does not always follow the typical turn-taking found in other conversations, erratic and often negative conversational patterns become the norm. Describing an erratic and negative conversational pattern one mother (M003) explained that at times when she asks her son to comply her son gets "cra...zy to the point that he cannot hear" her and she cannot get him to stop what he is doing and listen. Another mother (M008) said when she is trying to instruct her son she feels as though her son "doesn't speak English; he is not a native speaker." She has to tell him to stop what he's doing, look at her, and listen. Another mother (M009) experienced the erratic and negative communication pattern by stating that when things get out of hand with her daughter she feels "Exhausted. I would say it's not like losing your cool, but I feel like an abused spouse. She is walking away and won't respond to a verbal command. What else do you have? I don't know what else to do.” The erratic and negative conversational 
pattern of escalated conflict, screaming, arguing, and negative relational behavior becomes the pattern that many mothers expect when managing the conversation with their ADHD child. In short, the erratic conversational patterns between the mother and ADHD child become a predictable pattern of communication.

When asked to talk about how the mother perceives the ADHD child in these negative communication exchanges and moments, the mothers stated that they often believed the ADHD child was unaware of the affect he/she had on the mother, especially in the heat of the moment. Mothers also stated that after receiving professional help that the child was aware of the affect on the mother. Mother (M006) stated that her son says "I know how to unlock mean Mommy." As this mother continued her explanation of "unlocking mean Mommy" she stated that "he obviously doesn't like it when that happens as his feelings get hurt and he feels demeaned." As with the case with all the mothers, this mother (M006) expressed concern about what the negative pattern of communication was doing to the psyche of the ADHD child. "I worry what the yelling will do to his self-esteem in the long run." In addition, mothers reported having guilt after the negative communication exchange and reported that they try to counter those feelings by telling the ADHD child how much she loves him/her.

The relational management of a child with ADHD became apparent when the mothers talked about the need to be communicatively proactive with her child before a situation gets out of control and yelling ensues. For example, one mother (M007) has changed her approach with her son when she recognizes the beginning stages of the erratic conversational pattern. She stated that when her son's voice gets louder during disagreements she will say, "We are just talking. Why are you yelling? This is not a 
fight." She also recognized that she had to get out of the habit of negotiating with him because he uses negotiation as a tool. "The next thing you know you have negotiated a treaty for an entire nation that will bring peace to the world."

Another strategy of managing the ADHD child that the mothers revealed during the interviews was talking during the evening hours in the child's bedroom. If an outburst or a major argument occurred, the mothers were able to talk about it with their children during this time. It's at this time that mother and ADHD child discuss what they both could have done differently, as well as what they can do in the future to avoid the negative communication situations. For example one mother (M005) said that her son likes to talk to her after he is tucked into bed. Her son is more receptive to communication and he can process it better because he is in his "comfort zone." It is during this time that she capitalizes on talk time because being in his comfort zone allows him to be more receptive to conversation as well as comprehend it better. Similarly, another mother (M001) made this point by saying that she has established a "safe zone" in their house. If the son has a problem or if something is bothering him, he will ask for time in the safe zone with his mother or his father to talk about whatever it is that is going on. The way these mothers reach their ADHD child through these types of conversational strategies is important because they have found a way to get the ADHD child to listen, a proud feat for these mothers.

While the above communication techniques worked in some cases, during the interviews the mothers did not concentrate on the effectiveness of the strategies for very long. Instead, the mothers moved the conversation to the extraordinary amount of energy 
it takes to manage the situation, their own emotions, and the emotional state of the ADHD child.

A great deal of time during the interviews was spent with the mothers talking about the relational management of the ADHD. In addition to the unpredictable erratic communication patterns, the mothers described the relational management occurring during three other distinct times: when giving directions, during times of discipline, and times when the child is unable to focus or is impulsive.

When mothers try to give the ADHD child directions, much of the time is met with frustration and the mothers talked about trying to avoid "a total meltdown." One mother (M003) was trying to teach her six-year-old son how to ride a two wheeled bike. While she was teaching him he got frustrated, cried, talked over her, and "went into his own world." She stated she knew she had to handle the situation before it spiraled out of control. "I grabbed him, looked into his eyes, and sternly told him to calm down and listen." She stated it took her direct style of getting his attention, that may have appeared harsh, to break the negative spiral.

When giving directions, mothers reported that the emotional state of the child is apparent. Mothers often gave examples of the fragile emotional state of the ADHD child. One mother (M005) gave an example that when a new task was asked of her son she had to go through emotional cheerleading with her son. "He thinks he is stupid. I have to talk him through it. I have to show him he can do it." Another form of emotional cheerleading that was part of the relational management of the ADHD child was countering the "I'm going to fail" attitude of the ADHD child. Mothers expressed that the child is so afraid to fail that he/she won't even try the new task. The mothers talked about strategies of 
pushing the child to do the task, giving the child an exaggerated amount of emotional support before, during, and after the task, and giving detailed explanations of the task to help comfort the ADHD child. This type of relational management was often reported as a comparison to the non-ADHD child. In that, the mothers would say "I don't have to go through this with my other child."

The comparison to the non-ADHD child also emerged during conversations of discipline. A common theme was the difference in the relational management of how to engage in disciplinary action with a non-ADHD child and an ADHD child. With the nonADHD child, the mother can either say the punishment once and the child will comply, or give a warning to get compliance. They are also able to delay punishment where the child is still able to make a connection between the act and the consequence. The mothers report little relational management occurring during those moments. On the other hand, the ADHD child's behavior revolves around receiving immediate rewards and losing immediate privileges. If the consequences don't happen in the moment of the act the mothers report that the child won't be able to make the connection between the punishment and the behavior. The mothers stated that the management of doing the punishment in the moment does not always lend itself to "handling it in a private manner." Punishment must be handled in the moment whether the ADHD child is "at home," "at the store," or "in the yard in front of God and everybody."

Mothers stated that the ADHD child is often being disciplined because of impulsivity problems. Most of the time, when a child got into trouble, it was because of an impulsive act or because he or she did not think before speaking. These types of issues then become moments that require the mother to manage the ADHD child and the 
situation. For example, one mother (M002) told of a story that her child let his impulsiveness and love for shiny objects get the best of him. When he was at a picnic at his mother's boss's house he took her grandmother's watch, not maliciously but 'because it was shiny and he thought it was cool." The mother had to step in and explain the impulsiveness of her child to her boss and then re-explain to her ADHD child impulse control. Another mother's (M004) son acts impulsively with his choice of words. She said she is "always picking up the pieces" with him because "he doesn't always think before he speaks." For example, she told of the time when her ADHD son was "being picked on at school, so he threatened to bring a gun to school and shoot everybody. He was in second grade at the time, did not realize what he was saying, but he had to receive counseling for the entire summer before the school would let him back into the classroom." The mothers reported the endless explanations they give to the ADHD child about behavioral choices and managing the "aftermath of doing this kind of stuff all the time." One mother (M006) told the story of how her son rode his bicycle into the street without looking before his diagnosis. This same boy recently dove into a car on an airport tram just as the doors were closing. (M008) mentioned the time when her then 12-yearold son decided to spray paint his bicycle while the parents were away. He took the bike and the spray paints and painted his bike in his parents' bedroom. "I thought, what were you thinking. He wasn't thinking." When situations like these occur, it's "what could happen next?"

In addition to relationally managing the ADHD child, the mothers also talked about the anxiety they have about having another child(ren) whom they treat very differently. They also talked about getting caught up in what their affected child is doing, 
and they have to give themselves reminders to "stay on the other children." Sometimes when the non-ADHD child is reprimanded it is met with questioning the punishment in terms of fairness in comparison to the ADHD sibling. The mothers have to remind the non-ADHD child that both children are being treated fairly; they are just being treated differently. The children also have to be reminded that they are two very different people, and different consequences may apply to the same act. The mothers were articulate in stating the cognitive and rational explanations they give to the non-ADHD child, but the mothers also highlighted the fact that they agonized privately about the different approaches and reactions of the children. The mothers worried if they were "doing the right thing" when looking at how they treat the non-ADHD child and the ADHD child. They talked about seeing the faces and body language of the non-ADHD child when they are given the explanations of differences in punishment. The mothers often talked about giving the non-ADHD child alone "mommy time" to compensate for the often unequal attention given to the siblings.

The women in this study reported that managing relations within the household is an all consuming job for them. They talked about having an ADHD child forces them to take on more formal and deliberate roles such as teacher, negotiator, and disciplinarian. They report they don't have the same intensity of these roles with their non-ADHD children and try to manage the non-ADHD child with more mother-child alone time.

In addition to internal relational management all the mothers in this study reported they were concerned with how they managed communication about their child's ADHD outside of the home with non-family members. For example, if the ADHD child is participating in an outside activity or a sport, the mother must decide how much of their 
child's condition they should communicate with the coach or group leader, or if they should even give them any information at all.

One issue that consistently emerged was mothers not being sure how to respond when completing forms for participation in a sport or activity. For example, one mother (M006) registered her son for a martial arts class, and a question on the registration form asked if the child had any medical conditions. The mother responded, "No". However, further along on the form, there was a question which asked why she was registering her son for martial arts class, with one of the choices being because of ADHD. She circled the ADHD choice, but she also felt confusion as to whether or not she should have listed ADHD as a medical condition.

One mother in the study (M008) is completely open with coaches because if her child is participating in a sport, she says that she will tell them to "let them know that he is on medication and he's in an athletic setting, and it's important to let them know what the child is taking for safety reasons." An additional reason to be open with coaches is “so they realize it...I don't want to say it so they're more forgiving, but so they don't get frustrated, so they realize there is an issue. We need to talk to him differently (M003)." These mothers are not looking for acceptance from the coaches; they are looking for the coaches to acknowledge the child's unique situation in a nonjudgmental way. However, this type of openness with coaches can also backfire, as experienced by one mother (M004) when her then five-year-old son was playing soccer. The coach knew about her son's ADHD but instead of "dealing with it", he shunned the child and made him sit on the sidelines. 
The coach's response in this situation leads some mothers to not wanting or refusing to tell anyone about the child's ADHD diagnosis. One of the words that most often came up was stigma. One mother (M005) explained she didn't want to talk about her son's ADHD because she doesn't want her son to be perceived as “different." She further noted that she will not talk about her son's diagnosis with other mothers because she does not want her son to be stereotyped, avoided, and not be invited anywhere. As another mother put it (M006), "The stigma that is associated with ADHD is often worse than the reality of ADHD."

The issue of managing external relationships also crosses into the educational arena. For example, the mothers talked about their children having warning signs of impulsivity, not paying attention, and not focusing in school, but the reaction of the teachers, administrators, or other mothers drastically changed once warning signs were labeled ADHD. For example, some mothers reported having the "Oh. That explains it" reaction when they told the teachers about their child's diagnosis. This reaction left the mothers feeling like their children were then exposed to all the labels, misconceptions, and exaggerated descriptions of ADHD, and it was the mother's role to defend her child from the educators.

For example, one mother revealed (M008) that another mother whose children attended the same independent school, blatantly told her to stay quiet about her son's ADHD. This mother has a daughter with ADHD, but felt this particular school held a significant stigma about this condition. This particular mother overheard the head of the school talk about another independent school in the area that specializes in ADHD. The 
way the head of the school talked about this topic gave the mother the perception that ADHD children "don't really have a place at her school."

The mothers in this study revealed that feelings of stigma made it more difficult for them to talk about their child's condition with others. One mother (M002) described it as extremely difficult to talk about because "although it's a medical diagnosis it is not socially the same as admitting that your child has a peanut allergy." By not talking about the condition perpetuated that some of the mothers worried they too carried some of the stigma within them. For example, one mother (M005) stated that if she told people about her son's condition then she worried he would be treated differently and thus hurt emotionally. If she doesn't tell others about his diagnosis then she is continuing the cycle of silence about ADHD and buying into the notion that a "diagnosis of ADHD means labeling my son ADHD and all the negativity that comes with the label."

In summary, the mother is constantly dealing with internal conversations and issues with her ADHD child, while recognizing that the conversation isn't always going to be easy. They must capitalize on those times when they know their child is receptive to listening. At the same time, mothers are managing communication about their child's ADHD with outsiders knowing that in the backs of their minds there is a stigma attached to this disorder. However, they want coaches or other group leaders who are working with their ADHD child to acknowledge the condition so that it can be properly dealt with. Managing internal and external communication takes place while the mothers are also trying to manage the day-to-day operations in the household to keep the family functioning. How mothers manage the day-to-day operations is a function of the next theme which is Time Management. 


\section{Time Management}

Time Management was the second theme that emerged from the mothers in this study. Repeatedly mothers spoke about issues of time with the ADHD children, in that the ADHD child requires more time and that the ADHD child does not often have a conceptualization of time. Specifically, the mother becomes the "keeper of the time" for the child to prevent the child (and family) from straying from the task and/or schedule. In addition, the women talked about making time for non-ADHD children, their spouses, and having no time for themselves.

Extensive discussion in the interviews revolved around how the family dynamic is complex because of one person needing more attention than other family members. In particular, morning routines are particularly difficult for the mothers of the study. They talked about needing to "keep the tempo moving" and acting like "an assembly line worker" so it lessened the time involved with getting the children to school and parents to work. They stressed that if one step goes wrong the entire process gets thrown. In other words, if the mother (or ADHD child) veers from the morning tasks (e.g., brushing teeth, having breakfast ready) the day starts off with complete chaos and more time is involved with basic routine behaviors (e.g., putting clothes on in 30 seconds or 30 minutes). One mother (M007) explained this process as “I'm constantly trying to keep everyone in their places while keeping everyone heading out the door." In addition, the mothers emphasized that much of the morning routine needed to take place the night before with clothes ready, school bags packed, and breakfast orders taken. There seemed to be an extremely large amount of time involved the night before prepping for the morning routine and to keep the process moving. As a side note, it is important to mention that 
many of the mothers talked about the morning routine needing to be an assembly line because the child's medicine was not in his/her system yet. Without the help of the medicine, the mothers talked about the stress of constantly anticipating what was going to happen next, or what could potentially go wrong. For example, one mother (M001) said that "Typically, when I get home from working out at 6:40 in the morning, I give [my ADHD son] his medication at that time, and I can typically tell then when I give him his medication if it's going to be a good or a bad morning. Because he definitely wakes up on either the wrong or right side of the bed, and I will make the decision then as to whether or not they [both boys] are getting on the bus at 7:55 or if I'm going to wake them up at 8."

In relation to the morning, many of the mothers talked about the time involved to waking up the ADHD child in the morning and whether or not to let them sleep longer to prevent "a bad morning". Many mothers stated that it often takes multiple attempts to wake an ADHD child and that they usually wait until the last possible minute to wake their child. For example, one mother (M008) wakes her 13-year-old son only 15-20 minutes before they need to leave for school. Another mother (M006) allows her eightyear-old son to sleep until the last possible minute, where he is then ushered to the kitchen table where his breakfast and medicine are waiting for him. She describes the morning routine as "keeping him corralled," "keeping his area as contained as possible," and "keeping him moving from station to station." The goal is to get him through the morning with as little distraction as possible so less time is involved with morning routines. "There are times he gets away from me" which makes it a stressful drive to school because she has given him "until the last possible minute for sleep." 
All of the mothers in this study have their children come down to the kitchen for breakfast dressed in clothes that were laid out for them the night before, or they dress after breakfast where they will find their clean clothes waiting for them in the living room. As mentioned previously, some of the mothers actually plan what their child will eat for breakfast the night before. One mother (M008) has such discussions with her ADHD son, and he will usually eat whatever is left-over from dinner such as a bowl of pasta or some chicken. This mother will put the leftovers in a bowl, place the bowl in the refrigerator, and heat the leftovers in the microwave the next morning. There is room for negotiating a different breakfast as long as it doesn't require additional time. As this mother explains (and a held sentiment across many interviews), routines and decisions need to be thought out before the moment. There is time involved getting the morning routine ready but it eliminates the "kid with ADHD and no medicine in his system" to have to make another decision that could slow the process down or create a timeconsuming and emotional battle.

The morning routine plays out as a streamlined process in order for the day to begin on a positive note. Some mothers even keep the child's toothbrush on the main floor with the toothpaste already on the toothbrush so that the child does not have to go back upstairs and risk being distracted. While all of this is going on, the non-ADHD children are getting themselves ready for school on their own. Unlike their affected siblings, these children do have a concept of time, and they have learned to adapt to make the process run smoothly. One mother (M009) said that "my boys are self-motivated to get ready in the morning. While I'm spending time on [ADHD child], they are getting up, getting dressed, and pouring their own cereal." Another mother (M005) said that while it 
is difficult to get her ADHD son moving in the morning, it is contrasted by the way her other two children manage the morning routine. "(My non-ADHD son) just zips right out the door because he has to get the bus at 6:45 and he doesn't want to miss it. That's his motivation and (my non-ADHD daughter) just does it."

Managing time after school can also be stressful for the mother of an ADHD child. All of the children (ADHD and non-ADHD) in this study participated in a sport or activity. Some of the activities mentioned in the interviews were swimming, crosscountry, basketball, field hockey, horseback riding, Girl Scouts, and/or Boy Scouts. The mothers reported a difference in how much time is involved with the ADHD child's activities and the non-ADHD child's activities. In short, the difference is that most of the non-ADHD children were reported as having internal motivation to complete their homework and studying on their own. This motivation made it less time-consuming and stressful for the mothers in the study. Mothers, in contrast, reported that the ADHD children needed more time because the mothers had to push the child to complete homework, sit with the child, and often do homework in small time fragments in order to get all the homework completed. An example would be from a mother (M005) who said that her ADHD son will get home from school at 3:25, but not begin his homework until she gets home from work at 3:50. She has to scramble to help him and get dinner ready for 5:00 "because somebody always has somewhere to go." On the other hand her tenyear-old daughter (the ADHD child's twin) comes home and immediately does her homework. Another mother (M004) described her after school time as a big rush because they start homework as soon as her son gets home at 3:45, they go to swim practice, and then come home at 8:30, eat dinner, and finish any remaining homework. 
The mothers often reported the length of time it took before homework could be completed with the ADHD child. As one mother stated (M004), "It is stressful for both of us because we usually go through a "big blowup" before we can sit down and begin his homework. . . I'm never sure how long it's going to take as a page and a half of homework can take him anywhere from ten minutes to two hours to complete." Another mother (M003) will give her son a snack, sit down with him while he practices his math problems and sight words, and then he will practice the guitar. She doesn't allow him much down time so that he stays on task.

The mothers reported that the after school time is stressful for these mothers but they stated that outside activities were important for ADHD children. As one mother (M004) explained, "We use swimming as a way to keep him active and to keep him focused. I mean if he didn't have swimming he would be at home every night either trying to be in front of the video game, or in front of the T.V., or playing with kids he doesn't need to be playing with. So this is a way to keep him focused and to keep him out of trouble."

Many mothers reported that "a day in the life with an ADHD child can be all consuming," such that the other child(ren) in the household may not get as much attention as the ADHD child, and the spouse may also receive less time. One mother (M001) complained that she hasn't had a date with her spouse in three years. Another mother (M007) said that when her children were at the ages where they needed a babysitter, nobody could control their son. Therefore, she and her husband would take turns taking care of the children while the other spouse went out with friends. Finally, (M009) described her situation as not having any alone space. Her daughter finds her way 
into their bedroom every night, so there is never uninterrupted sleep. She also said that her day feels like it's always compressed because many times she finds herself spending two hours working on a schedule to help the ADHD child. The amount of time that mothers spend on her child's ADHD issues causes her to experience much stress. All of the mothers in this study acknowledged their high stress levels and they all recognized the need for emotional and practical support to help them through trying times. As such Internal and External Support was the final theme uncovered in this study.

\section{Internal and External Support}

The third theme that emerged in this study was internal and external support. There are two ways that support emerged for mothers of ADHD children. Internal support refers to the emotional and pragmatic support they receive from their children and their spouses. External support refers to the pragmatic and emotional support they receive from those outside the family such as from professionals or friends. Emotional support is conceptualized by the mothers as having someone they can turn to for verbal support or advice in managing the ADHD child. The person who provides the most emotional support is the spouse. However, the ADHD child's siblings can also provide this kind of support. Pragmatic support is defined as the practical support in being able to help find solutions to make the living situation better versus creating more problems. This support usually comes in the form of advice from a professional, teacher, or friend. It also appears that most of the emotional support takes place internally, while most of the pragmatic support comes from the outside.

Throughout the interviews, the women spoke of the need to have a support network so the household can operate as harmoniously as possible. The mothers talked a 
great deal about the other child(ren) in the household and how these siblings have adapted their behavior to help the household run more smoothly. The mothers acknowledged that these children recognize their ADHD siblings get more attention, and they also recognize the difficulty communicating with the ADHD child. The mothers remarked that the non-ADHD child(ren) adjusted their behavior positively, instead of going against the system and making situations potentially more difficult on the parents. Many mothers remarked that the non-ADHD child(ren) have found ways to become part of the "family team." Many mothers stated that instead of the non-ADHD child having the "what about me attitude" he or she now has the "it's all about us" attitude. They have gone from a "me" to a "we" approach to in order to help foster positive relations in the household. For example, as one mother stated, when one sibling sees that her ADHD brother is taking too much time to get ready in the morning she will cope by telling her mother that she will be waiting for them in the car. Other ways that siblings have adapted is by using humor. One mother reported that one sibling of an ADHD child, said to her mom (M007), "Ma, are we always going to have to be the normal ones in this house?" This particular family is dealing with an ADHD child living in the household, but they are also dealing with the male parent/spouse's ADD diagnosis. Another mother's (M008) two older daughters will affectionately tease their ADHD brother that he is "being really ADHD right now" when he is acting impulsively or if he loses track of time. The mother said that they "call their brother out and then he laughs."

Other children may not be so blatant in the way they interact with their siblings, but recognize that they need to adapt to get their sibling's attention. One mother (M004) stated that she noticed that her non-ADHD son figured out that yelling across the room to 
get his ADHD brother's attention does not work. She said, "If he wants his attention, he knows he needs to approach him, tap him gently on the shoulder, make eye contact, and call his brother's name."

Having the siblings on board with the way the family functions is part of the process the mothers talked about in order to have a "functioning family." These mothers also commented that it's as important or even more important for the spouse to provide emotional support to the mother. It was noted across several interviews that the amount of support a mother receives is often dependent upon how much they agree with the diagnosis and treatment options. As such, many of the mothers commented on the lack of support or negative emotional support they received from their husbands in the beginning phases of managing the ADHD child. One mother (M004) said that in the beginning her husband was the most stressful part of receiving their child's diagnosis because he didn't believe in the diagnosis, therapy, or medication. She only started to receive support from him when she threatened to leave him. She reported after that punctuated event, that he is trying to "get on board." This mother further noted that the family unit defined themselves using a funny acronym using the letters of ADHD. "He [the older affected son's name] has more of the Attention, the A, [the unaffected child's name] has more of the Hyper, the H, and I have the D, the Depression. My husband, his D is the Denial in all of this."

Another mother (M003) does have a spouse who believes in the diagnosis, but he looks for the quick fix and doesn't always support her. She stated that "he looks for a fast solution and that it takes a really bad day followed by family meetings to get temporary agreement in the household." When her husband reverts back to what she calls "his 
former ways" she gets frustrated and feels a lack of emotional support from him. A third mother (M007) said that there were times her husband would pull himself out of the situation where she felt it "left her high and dry." She understood his "frustration and pain", and yet she had to push him to be involved after she had already been fighting with their son. She had to learn to go to her husband, who would be "wiped out," verbally recognize this with him, and then tell him that she needed him. This mother commented that they "have had to learn to work together and openly communicate with each other so that they could become a team."

It is not always the case that mothers are lacking in emotional support from their spouses, especially if the spouses were not surprised by the diagnosis. Those mothers who reported the most emotional support take a "team approach" by taking turns in terms of dealing with the children. At the same time, these mothers stated that the parental unit (both the mother and father) recognized that they (parents) may be "completely spent," but "one of them has to deal with the situation at hand." For example, one mother (M009) recognized that her husband is the calmer person and "he will more easily remove [ADHD child's name] from the situation and bring her to her bedroom." On the other hand, the mother commented that if she tried to remove her ADHD child that "it would be a dragging thing, physical." Another mother (M006) sees her husband's strengths in being able "to step back from a situation, let it go, and give it time." This strategy indirectly helps the mother get through a conflict that could be taking place with their child. Still another mother (M005) reported that she and her husband talk about their son's ADHD all the time and they are on the "same page with treatment and discipline." In all, the team approach seems to be a coping mechanism for these mothers. One family 
best captures this team approach by referring to themselves as the "H-Team." The mother commented that the "H-Team" is also what is imprinted on their license plate.

In another household the mother (M001) reported that she and her spouse have what she describes as "a very good pattern of communication." She stated, "He [husband's name] can pretty much walk in the room and look at my face, and I can look at his face and see he's had enough, or I've had enough. And say, hey [son's name], can I take in, so [son's name] doesn't know we're doing it, but it goes back and forth." In (M002)'s household, she and her husband have to remind each other that sometimes it's an ADHD issue and not an "irritating nine-year-old." It seemed across the interviews that these checks and balances help kept the momentum going in the household so that the appropriate decisions can be made about discipline or about how a certain situation needs to be handled. The use of open communication, non-verbal cues, and having the siblings on board with the living situation makes life a bit less stressful for the mothers.

No matter how much internal support is provided, the mothers reported that sometimes it is necessary to receive support from the outside. From a pragmatic point of view, the help of a professional can assist the mothers in being able to better handle the ADHD child. All of the mothers in this study are currently employing the help of a social worker, therapist, child psychologist, or child psychiatrist. All of the ADHD children and some of the family members see a professional so they understand how to manage the ADHD symptoms and behavior. Across the interviews it was stated that many of the communication and discipline strategies as well as how mothers manage their days have been developed with the help of a professional. For example, one mother (M003) realized 
with the help of the psychiatrist, that she was giving her son too much down time after school and she needed to reduce that time to keep him on task with his homework and guitar practice. The psychologist that (M002) uses for her son gave her the okay to let him play his video games and watch television for an hour each day as it's his way to decompress at the end of a school day. This mother stated that it was this type of practical advice that helped her a great deal.

Other ways that trained professionals help is in terms of medication management. All of the mothers in this study use a combination of ADHD medications to manage their child's symptoms. For seven out of nine of the mothers in this study, deciding whether or not to medicate their child was one of the hardest decisions they had to make in relation to their child's ADHD. Most of them could understand the meaning of "administering Tylenol for a fever with the dosage given based on weight or age." However, they couldn't understand medication that would have "fits and starts" in terms of not only what the right dosage would be, but which medication would work the best.

The mothers in this study said that medicating the ADHD child was "the right decision" and that their "child might not be enrolled in a regular education classroom environment if it wasn't for the medication." One mother (M001) specifically stated that her ADHD son would be in a learning disability class if he was not taking ADHD medication. Instead he is in a regular classroom making the honor role. Another mother (M006) is a psychiatrist who prescribes many of the medications used to treat ADHD. However, making the decision to put her own son on medication was clearly the hardest decision that both she and her husband had to make for him: 
I was certainly worried about the side effects of the medicine. And then as we've gotten into it, which is what we've experienced and what happens with a lot of patients is that you don't get that WOW drug the first time around. Having to get that merry-go-round, of trying this, having problems, and having to live through those problems, side effects, try something else and have those problems. It's just as frequently people come in and they thank me for whatever. Hey, what I do is really easy, but it's hard and as a parent, you have to sit back on pins and needles and worry are they gonna have this side effect, or what's it gonna do?

(M008) was able to make the decision to place her son on ADHD medication only after taking advice from her mother-in-law who is a licensed marriage and family therapist. She was able to provide her son and daughter-in-law both the pragmatic and emotional support they needed while they were going through the decision making process. The mother-in-law compared the fact that (M008) has to wear glasses and that "asking her son to go through his day without medication is like asking her to go through her day without her glasses. It's not fair to him."

Other professionals that provided both pragmatic and emotional support to the mother are their child's teachers. All of the mothers spoke freely about their child's ADHD with teachers, and they do so in fairness to the child, because the child has an I.E.P., or may be taking medication. The "team approach" that the mothers and their spouses use at home can also work for the mothers and their child's teachers. Once again time was a factor that the mothers used to describe issues with teachers and the ADHD child. The mothers in this study stated they have to be much more involved in the minutia of their child's education. For example, one mother (M005) has boy/girl twins who are 
ten years old, with the boy having ADHD. When she was asked how much more time she spent talking to the teachers about her son versus her daughter, she said the amount of time was double.

The amount of support that a mother receives from the teachers can make a difference in the ADHD child's educational experience. One mother (M001) explained her relationship with her son's teacher as “They will call if there is an issue with [child's name] at school, but even more importantly, they will call if they see something off with his behavior that could be attributed to the medication." In another example, one mother's (M002) ADHD son was enrolled in a public school from kindergarten through second grade. The child's second grade teacher could not comprehend his condition. She stated, "We kept saying, if you had a child who had epilepsy or diabetes you would make concessions. You would create a plan for this. The teacher just said well that's not fair. We don't let these other children do that. Well the other children don't have ADHD." The mother further explained that the ADHD child was "labeled as being below average at this school. He now attends an independent school that does not specialize in ADHD, but at his new school he is performing two grades ahead of his fourth grade class." Across the interviews the mothers expressed that the kind of an experience a child has at a particular school makes it even more difficult for some families to decide on a new school - they did not want to "make the same mistake twice" by choosing a school and teachers unable to handle an ADHD child.

Another mother (M007) received assistance from her own mother in trying to choose a school for her ADHD son. She provided support by laying the groundwork and 
gathering information about specialized schools and guided her daughter and son-in-law through the process. Other family members may not be so forward in their support, but the parents knowing that they are on their child's side is enough for them.

Many of the mothers stated that other means of emotional support come from their friends who understand what the mothers are going through on a daily basis. One of the mothers (M007) has an agreement worked out with one of her neighbors who she also happens to be friends with. If her non-ADHD child knocks on their back door, they let her in. The neighbor understands that a conflict is taking place at her house and she needs to get away from the situation. At the same time (M007) has a spare key to this neighbor's house because their daughter has anorexia and she sometimes locks the parents out of the house. She described this arrangement as "swapping worlds." She also said that she has told a few neighbors, but not every neighbor "because not every neighbor gets it."The idea of not every neighbor getting it also comes through with friendships. This same mother (M007) also knows which friends she can and cannot talk to about her situation. For example, this mother stated she has a lawyer friend who is described as having the "Oh. Let me solve the problem for you response." When her family is experiencing some of their roughest times she does not call her to tell her about her problems. If she sees her in a social setting during those times it's okay, but anything more than that is too stressful for this mom. The mothers realize they cannot speak about their ADHD child's issues with other friends who are parents. As one mother (M004) says “Don't go asking your friend and say my kid did this, and what do you do with yours? It doesn't work. It doesn't work." 
Although mothers did talk about the support received from friends, some mothers expressed that feelings still get hurt because friends can give emotional support but not practical support (i.e., babysitting or watching an ADHD child). As one mother (M002) stated "Everyone [friends] was really supportive. But one time my feelings were hurt when um, a friend of mine who is just a dear, dear friend, and she is very supportive. One time she said I cannot watch [son's name] because I just am afraid I can't control him. I was so glad she was honest with me, but it hurt."

All the mothers stated during the interviews that internal and external support from family, friends, and professionals was important. One mother (M005) best stated that because of the support she received she felt "there was light at the end of the tunnel." These women seem to be managing the family better because of the support they receive.

\section{Summary of Results}

There are certainly challenges that go along with raising an ADHD child in terms of managing relations in and outside of the home, managing time, and getting the needed support. However, there are also many rewards that come with raising these children. Most of the rewards are rewards that a parent of any child would experience. Seeing a child achieve, and being able to raise a happy, funny, affectionate, caring, and sensitive child is what many parents want to see from their children. As one mother (M003) stated "I live for those soft moments when I know at the end of the day [child's name] loves me." This same mother (M003) explained it as "Kids with ADHD are sometimes harder to love but they're the ones that need the love more." It is the combination of the mothers feeling loved and appreciated, watching their child achieve and be happy while at the same time "taking a break from the ADHD" that keeps these mothers going. It seemed 
across all the interviews that the mothers struggled with understanding the family communication due to having an ADHD child. One mother (M007) best captured this feeling by saying that she and her husband are constantly changing the way they communicate because they have an ADHD child. In all, the mothers of this study have made strides in learning how to better manage and understand the communication process. 


\section{DISCUSSION}

Mothers wear many different hats, and taking care of a child can be rewarding, but also very stressful. The results from this study have demonstrated that the mothers with a child diagnosed with ADHD spend the majority of their time managing, talking about, and worrying about ADHD issues. Whether it's the morning routine, managing after school issues, or talking about their child's ADHD with outsiders adds an everpresent level of stress in these mothers' lives. The mothers are constantly juggling the roles of the emotional cheerleader, the teacher, the disciplinarian, the negotiator, time keeper, and gatekeeper of information. The mothers recognize that they need emotional support from other immediate family members, but they also recognize they need the help of a professional. As mentioned previously, all of the participants in this study are currently under the care of a therapist, psychologist, or psychiatrist for the children's medication management and for assisting with parental communication strategies.

Tripp et al. (2007) suggested that the manner in which families communicate and their overall dynamic is affected by whether or not a particular family has an ADHD child living in the same household. The study also showed that there was also more warmth displayed when communicating with the non-ADHD child. This current study also demonstrates that having an ADHD child affects the overall family dynamic and how family members communicate with one another. From getting ready in the morning 
to disciplining the child, there is always more to consider when there is an ADHD child living in the household. In addition, as many of the conversation patterns with the ADHD child are erratic, it is harder for the mothers to exude as much warmth as they are constantly "on guard."

In this current study, according to the mothers, the spouses who provided the most emotional support from the beginning believe that the child has a medical diagnosis, are sympathetic to the child, and believe the condition is a part of them as a person. They are also more open to evaluating different treatment options such as behavioral modification as well as medicine. The fathers who do not believe in the diagnosis provide the least amount of support and do not want to consider medicine. All of the children in this study are taking medication to manage their symptoms. In this current study, putting the ADHD child on medication was one of the toughest decisions both mothers and fathers had to make for their child but ultimately decided it was the right choice for the child.

Gerdes et al. (2006) demonstrated that mothers believed their ADHD children were not misbehaving on purpose. They also recognized that the ADHD children's behavior was less controllable and intentional. That study was based on mothers who were either a parent of an ADHD child or a non-ADHD child; they did not have both living in the same household. The present research is also able to demonstrate that the ADHD children and non-ADHD children behave in different manners with impulsivity being the number one issue with the ADHD children. The mothers understand that they need to repeat instructions in order to get them to comply with a request. They also understand that delaying a punishment would cause a complete disconnect between the 
offense and the consequences. This type of disconnect would not take place with the nonADHD children.

The study conducted by Kendall et al. (2005) demonstrated that the levels of distress felt by the mothers of an ADHD child is the barometer for how her ADHD child's behavior is managed, as well as how family conflict is addressed. This study also discussed mothers needing additional emotional support. In this present study, the feelings of stress were present throughout all of the interviews. In addition, those who receive the least amount of emotional support from their spouse also feel the highest amounts of stress. In addition, the way that the ADHD child needs to be spoken to versus the way the non-ADHD siblings are spoken to also affect the family dynamic. Where the ADHD child needs clear concise direction, the non-ADHD siblings can and are encouraged to converse.

Ritchie and Fitzpatrick (1990) posit there are two main orientations to family communication: conversation orientation and conformity orientation. Conversation is defined as "the degree to which families create a climate where all family members are encouraged to participate in unrestrained interaction about a wide array of topics" (Roskos-Ewoldsen \& Monahan, 2007, p. 205). Conformity "refers to the degree to which family communication stresses a climate of homogeneity of attitudes, values, and beliefs" (Roskos-Ewoldsen \& Monahan, 2007, p. 206). Children in conversation-oriented families learn to look at the concepts themselves when assigning meaning to them and to explore potential meanings by discussing them with others. The children who experience higher levels of conversation are able to navigate and make sense of their family interactions as 
they are free and encouraged to interact with each other; therefore there is also much sharing of thoughts and feelings.

The other orientation, conformity, stresses how much one is expected to share the same attitudes, beliefs, and values as everyone else in the family. The higher the level of conformity, the higher the expectation is to be similar. In these types of families "parents are expected to make the decisions for the family and the children are expected to act according to their parents' wishes" (Roskos-Ewoldsen \& Monahan, 2007, p. 207).

The present study was able to touch upon Ritchie and Fitzpatrick's themes of family orientation. In that, the differences in the communication process with the ADHD children versus the non-ADHD children are apparent in this study. It appears that there are two different family communication patterns present within the same household. For example, the ADHD children respond to clear instructions and are expected to follow the rules that are given (conformity). It is also noted that in terms of discipline, the ADHD children must have their consequences be in the moment so that a connection can be made between the punishment and the act. On the other hand, the conversation approach appears to work with the non-ADHD children.

This way of thinking falls in line with Gottman's emotion regulation theory which focuses on the concept of meta-emotions. Meta-emotions are defined as "emotions that people have about emotions" (Turner \& West, 2006, p. 215). Through his studies regarding meta-emotions, Gottman identified two types of parenting styles, those parents who are emotion-coaching (EC) and those who are emotion-dismissive (ED). According to Gottman, a parent is EC if they are "aware of their child's emotions, recognize the 
emotion as an opportunity for intimacy and teaching, listen empathetically, validate the child's feelings, help the child find words to label the emotion he is having, and set limits while exploring strategies to solve the problem at hand" (Gottman, 1997, p. 24). These parents also know how to state clear consequences to their children if they behave in an inappropriate manner.

On the other hand, an ED parent will minimize their child's emotions, criticize, belittle, and take over if the child is making a mistake. These parents will spend more time telling the child how to get over it versus understanding the emotion. They also do not know how to problem-solve and will rely on the concept of time to fix things rather than actively brainstorm a solution.

The mothers who were a part of this present study recognize that they can be emotion-dismissive, but it can be difficult to break the process. One mother (M004) says that she would really like to "eliminate the yelling." Another mother (M007) has the same sentiments and elaborated by stating "You would hear the things that would come out of your mouth, and you say I can't believe I am saying this to a child.” As normal conversations with an ADHD child can quickly escalate, it can be very difficult to try to avoid this type of parenting.

Gottman describes emotion-coaching parents as being able to listen to their child, problem solve, recognize their emotions, and know when to capitalize on teachable moments is the parenting style that both mothers and fathers of ADHD children should strive for. The mothers in this study who recognize when their children are receptive to conversation can more easily employ the emotion-coaching style that is necessary for the ADHD child to succeed. As mentioned previously, when the mother can get her child 
into his or her comfort zone or safe zone, she can truly speak with her child. These results also demonstrate that emotion-coaching behavior can be more positive to the family dynamic in the long-run.

The idea that all members of the household are affected by the type or types of communication that are present in the household would lead to the belief that more research in this area would be beneficial to ADHD families. It would be of interest to pursue conversational and conformity family orientations and emotion regulation theory in terms of how children who are a part of a household with an ADHD child perceive family communication. This kind of information would be invaluable especially if the data was derived from both the ADHD and non-ADHD children. Future studies should focus in this area so that enough data is generated in order to provide recommendations on how to improve the overall family dynamic.

In addition, all the participants in this study were from two-parent homes. This fact can be viewed as a limitation in this study. Kerr et al. (2007) found that those ADHD children who were part of an intact family had less hyperactivity and attention problems versus those who were a part of another family configuration. It would be interesting to see if these results are sustainable by comparing the results from the participants in this study with more single mothers who have ADHD children.

Another limitation to this study is that all of the mothers recognize that they need to receive professional help in terms of using a therapist, psychiatrist, or psychologist. This type of professional help assists them in being able to manage their ADHD child and household more efficiently. Everyone in the study receives help from a specialist, and 
they are aware enough to get that help and they have the means to do so. The fact that eight out of nine of the participants are mothers of boys is another limitation to the study. All of the boys seem to have a fascination with video games, computer games, and television, which are the activities of choice with each of them. This fascination does not seem to occur with the girl. It would be interesting to see if this difference would continue if more mothers of girls were included in the study. It would also be interesting to see if other differences would emerge. Finally, another limitation to the study is that all of the coding and thematic analysis was conducted by only one person. It would be of benefit to see if another researcher could find any other emerging themes. 


\section{CONCLUSION}

In conclusion, this study uncovers many communication issues present in the

ADHD household. It was found that the way that family relations and communication are managed in and outside of the household has to be deliberate. Mothers often play the roles of peacemaker, teacher, and negotiator when dealing with their ADHD child.

This study found that family communication revolves around the mother's ability to manage time. Mothers in this study must be the keeper of the time because the ADHD child has no concept of time. The mothers in this study noted that if they don't watch the clock chaos can ensue. Much of the household routine is planned "behind the scenes" in advance in order to keep the process moving. Time also has to be managed carefully while taking into consideration their child's tolerance for being able to complete a task in one sitting. The non-ADHD children in these households are able to start homework and finish it.

The stress and the lack of time the mothers have for other family members can only be worked through with emotional and pragmatic support from her other child(ren), spouse, friends, and professionals. These mothers stated they take a team approach in order for the household to be more peaceful. Further studies should explore how the family communication evolves as the child ages. As mentioned earlier, many of the symptoms of impulsivity diminish as the ADHD child gets older. How the changes in 
symptoms affect family communication needs to be researched as well as how the parents and siblings respond to those changes. 


\section{REFERENCES}

American Psychiatric Association. (2000). Diagnostic and statistical manual of mental disorders: DSM-IV-TR. Arlington: American Psychiatric Association.

Armstrong, T. (1995). The myth of the A.D.D. child. New York: Penguin Putnam Inc.

Chen, M., Seipp, C. M., \& Johnston, C. (2008). Mothers' and fathers' attributions and beliefs in families of girls and boys with attention-deficit/hyperactivity disorder. Child Psychiatry and Human Development, 39, 85-99.

Corbin, J., \& Strauss, A. (2008). Basics of Qualitative Research (3rd Edition ed.). Thousand Oaks: Sage.

Crawford, S. G. (2007). Specific learning disabilities and attention-deficit hyperactivity disorder: Under-recognized in India. Indian Journal of Medical Sciences, 61(12), 637-638.

Dukarm, C. P. (2005). Bulimia nervosa and attention deficit hyperactivity disorder: A possible role for stimulant medication. Journal of Women's Health, 14(4), 345350.

Edbom, T., Granlund, M., Lichtenstein, P., \& Larsson, J.O. (2008). ADHD symptoms related to profiles of self-esteem in a longitudinal study of twins: A personoriented approach. Journal of Child \& Adolescent Psychiatric Nursing, 21, 228237. 
Ek, U., Westerland, J., Holmberg, K., \& Fernell, E. (2008). Self-esteem in children with attention and/or learning deficits: The importance of gender. Acta Paediatrica, 9 (8), 1125-1130.

Ferrari, J. R. (2000). Procrastination and attention: Factor analysis of attention deficit, boredomness, intelligence, self-esteem, and task delay frequencies. Journal of Social Behavior \& Personality, 15, 185-196.

Fitzpatrick, M. A., Leutwiler, T. J., Krcmar, M., \& Marshall, L. J. (1996). The effect of family communication environments on children's social behavior during middle childhood. Communication Research, 23, 379-406.

Gerdes, A. C., \& Hoza, B. (2006). Maternal attributions, affect, and parenting in attention deficit hyperactivity disorder and comparison families. Journal of Clinical Child and Adolescent Psychology, 35(3), 346-355.

Goffman, E. (1963). Stigma: notes on the management of spoiled identity. New York: Simon \& Schuster, Inc.

Gottman, J. (1997). Raising an emotionally intelligent child. New York: Simon and Schuster .

Gregory, A., \& Rimm Kaufman, S. (2008). Positive mother-child interactions in kindergarten: Predictors of school success in high school. School Psychology Review, 37(4), 499-515. 
Guerrero, L. K., Andersen, P. A., \& Afifi, W. A. (2007). Close encounters: communication in relationships. Thousand Oaks: Sage Publications, Inc.

Johnston, C., Scoular, D. J., \& Ohan, J. L. (2004). Mothers' reports of parenting in families of children with symptoms of attention-deficit/hyperactivity disorder: Relations to impression management. Child and Family Behavior Therapy, 26, $45-61$.

Kendall, J., Leo, M. C., Perrin, N., \& Hatton, D. (2005). Modeling ADHD child and family relationships. Western Journal of Nursing Research, 27(4), 500-518.

Kerr, D., \& Michalski, J. H. (2007). Family structure and children's hyperactivity problems: A longitudinal analysis. Canadian Journal of Sociology, 32, 85-112.

McGuinness, D. (1990). Behavioral tempo in pre-school boys and girls. Learning and Individual Differences, 2, 315-325.

McNamara, J., Vervaeke, S.-L., \& Willoughby, T. (2008). Learning disabilities and risk-taking behavior in adolescents: A comparison of those with and without comorbid attention-deficit/hyperactivity disorder. Journal of Learning Disabilities, 561-574.

Montgomery, B. M., \& Baxter, L. A. (1998). Dialectical approaches to studying personal relationships. Mahwah: Lawrence Erlbaum Associates, Inc., Publishers.

National Institute of Mental Health. (2009, January 23). About us: National Insitute of 
Mental Health. retrieved August 5, 2009, from National Institute of Mental Health web site: http://www.nimh.nih.gov

Owen, W. F. (1984). Interpretive themes in relational communication. Quarterly Journal of Speech, 70, 274-287.

Padolsky, I. (2008). The neuropsychological and neurobehavioral consequences of ADHD comorbid with ld and otitis media. Journal of Developmental \& Physical Disabilities, 11-20.

Roberts, R. E., Roberts, C. R., \& Chan, W. (2009). One-year incidence of psychiatric disorders and associated risk factors among adolescents in the community. Journal of Child Psychology and Psychiatry, 405-415.

Roskos-Ewoldsen, D. R., \& Monahan, J. L. (2007). Communication andsSocial cognition: theories and methods. Mahwah: Lawrence Erlbaum Associates, Inc.

Smith, M. D., \& Barrett, M. S. (2002). The effect of parent training on hyperactivity and inattention in three school-aged girls with attention deficit hyperactivity disorder. Child \& Family Behavior Therapy, 24(3), 21-35.

Tripp, G., Schaughency, E. A., Langlands, R., \& Mouat, K. (2007). Family interactions in children with and without ADHD. Journal of Child \& Family Studies, 16, 385400.

Turner, L. H., \& West, R. (2006). Perspectives on family communication. New York: 
McGraw-Hill.

Weinberg, H. A. (1999). Parent training for attention-deficit hyperactivity disorder: Parental and child outcome. Journal of Clinical Psychology, 55(7), 907-913.

Wood, J. T. (2007). Interpersonal communication: Everyday encounters. Belmont: Wadsworth, Cengage Learning.

Zentall, S. S. (2005). Theory- and evidence-based strategies for children with attentional problems. Psychology in the Schools, 42(8), 821-836. 
Appendix A - (American Psychiatric Association, 2000)

The following diagnostic criteria for ADHD are specified in the DSM-IV-TR:

A. Either (1) or (2):

1. six (or more) of the following symptoms of inattention have persisted for at least 6 months to a degree that is maladaptive and inconsistent with developmental level:

\section{Inattention}

a. often fails to give close attention to details or makes careless mistakes in schoolwork, work, or other activities

b. often has difficulty sustaining attention in tasks or play activities

c. often does not seem to listen when spoken to directly

d. often does not follow through on instructions and fails to finish schoolwork, chores, or duties in the workplace (not due to oppositional behavior or failure to understand instructions)

e. often has difficulty organizing tasks and activities

f. often avoids, dislikes, or is reluctant to engage in tasks that require sustained mental effort (such as schoolwork or homework)

g. often loses things necessary for tasks or activities (e.g., toys, school assignments, pencils, books, or tools)

h. is often easily distracted by extraneous stimuli

i. is often forgetful in daily activities

2. six (or more) of the following symptoms of hyperactivity-impulsivity have persisted for at least 6 months to a degree that is maladaptive and inconsistent with developmental level:

\section{Hyperactivity}

a. often fidgets with hands or feet or squirms in seat

b. often leaves seat in classroom or in other situations in which remaining seated is expected

c. often runs about or climbs excessively in situations in which it is inappropriate (in adolescents or adults, may be limited to subjective feelings of restlessness)

d. often has difficulty playing or engaging in leisure activities quietly

e. is often "on the go" or often acts as if "driven by a motor"

f. often talks excessively 


\section{Impulsivity}

g. often blurts out answers before questions have been completed

h. often has difficulty awaiting turn

i. often interrupts or intrudes on others (e.g., butts into conversations or games)

B. Some hyperactive-impulsive or inattentive symptoms that caused impairment were present before age 7 years.

C. Some impairment from the symptoms is present in two or more settings (e.g., at school [or work] and at home).

D. There must be clear evidence of clinically significant impairment in social, academic, or occupational functioning.

E. The symptoms do not occur exclusively during the course of a Pervasive Developmental Disorder, Schizophrenia, or other Psychotic Disorder and are not better accounted for by another mental disorder (e.g., Mood Disorder, Anxiety Disorder, Dissociative Disorder, or a Personality Disorder).

The DSM-IV-TR specifies a code designation based on type:

314.01 Attention-Deficit/Hyperactivity Disorder, Combined Type: if both Criteria A1 and A2 are met for the past 6 months

314.00 Attention-Deficit/Hyperactivity Disorder, Predominantly Inattentive Type: if Criterion A1 is met but Criterion A2 is not met for the past 6 months

\subsection{Attention-Deficit/Hyperactivity Disorder, Predominantly} Hyperactive-Impulsive Type: if Criterion A2 is met but Criterion A1 is not met for the past 6 months.

Coding For individuals (especially adolescents and adults) who currently have

note: symptoms that no longer meet full criteria, "In Partial Remission" should be specified.

314.9 Attention-Deficit/Hyperactivity Disorder Not Otherwise Specified: This category is for disorders with prominent symptoms of inattention or hyperactivity-impulsivity that do not meet criteria for AttentionDeficit/Hyperactivity Disorder. Examples include: 
1. Individuals whose symptoms and impairment meet the criteria for Attention-Deficit/Hyperactivity Disorder, Predominantly

Inattentive Type but whose age at onset is 7 years or after

2. Individuals with clinically significant impairment who present with inattention and whose symptom pattern does not meet the full criteria for the disorder but have a behavioral pattern marked by sluggishness, daydreaming, and hypoactivity 


\section{Appendix B - INTERVIEW GUIDE}

1. Tell me about being a mom.

2. Describe some of the warning signs that you encountered where you knew something was different with your child.

3. What stressed you out the most about having your child diagnosed with ADHD?

a. How did you feel when you received your child's diagnosis?

b. Describe how your spouse reacted when he found out.

4. Tell me about life after the diagnosis.

a. How do you tell other people?

i. Family Members

ii. Teachers

iii. Coaches

iv. Other parents

5. Describe how mothering your child has changed since receiving the ADHD diagnosis.

a. How has your spouse changed his parenting since the diagnosis?

b. How have your other children changed the way they interact with their affected sibling since the diagnosis?

c. Describe the most difficult decision you have had to make for your child?

6. In your household, describe a typical day.

a. School day.

b. Summer day. 
7. Tell me about a time where your child got into trouble.

8. Describe some of the discipline strategies that you use with your other children.

9. If you are showing your child how to complete a new task, give an example of how this usually plays out.

10. Describe some of the strategies that you use when asking your child to complete a task such as homework.

11. If your request is met with resistance, how do you deal with it?

12. Describe some of the routines that you follow in your household.

13. Tell me about a time when your child had a problem that was solved.
a. What was the problem?
b. How was it solved?
c. Who solved it?

14. Give an example of a time when you really lost your cool with your child.

a. Describe how your child reacted to the situation.

b. Describe how you felt afterwards.

15. What kind of emotional support do you receive from your partner or spouse?

16. What is the biggest challenge in your marriage in relation to your ADHD child?

17. How has your communication with your spouse changed since the diagnosis?

18. What are some of the biggest challenges that you face with your child?

19. What do you find to be the most rewarding in terms of parenting your ADHD child?

20. What are some of the biggest challenges that you see your child facing because of the ADHD? 
21. Describe some of the communication strategies that you have found to work in terms of talking with your child.

22. What kind of an influence has the ADHD diagnosis been in terms of your educational choices for your child?

23. What advice would you give to other parents with children who have ADHD?

\section{Demographics}

1. How old are you? ___ years old

2. How do you describe your race/ethnicity?
a. White - Not Hispanic
b. Black - Not Hispanic
c. Hispanic or Latino
d. Asian or Pacific Islander
e. Other (specify):

3. What is your marital status?
a. Married
b. Divorced
c. Widowed
d. Separated
e. Never been married
f. A member of an unmarried couple 
4. Please list the ages and genders of all of your children and specify which children have ADHD.

\begin{tabular}{|l|l|l|l|}
\hline Age of Child & Gender & ADHD (Yes) & ADHD (No) \\
\hline & & & \\
\hline & & & \\
\hline & & & \\
\hline & & & \\
\hline
\end{tabular}

5. What is your highest level of education completed?
a. $8^{\text {th }}$ grade
b. $12^{\text {th }}$ grade/high school
c. Some college
d. Associate's degree
e. Bachelor's degree
f. Master's degree
g. Coursework above a Master's degree

6. How many hours a week do you work for pay? 


\section{Table 1}

Demographic Breakdowns

\begin{tabular}{|c|c|c|c|c|c|c|c|c|c|}
\hline $\begin{array}{l}\text { Age of } \\
\text { Mother }\end{array}$ & 35 & 37 & 41 & 42 & 43 & 44 & 46 & 47 & 48 \\
\hline Classification & $\begin{array}{l}\text { Mother } \\
\# 1\end{array}$ & $\begin{array}{l}\text { Mother } \\
\# 2\end{array}$ & $\begin{array}{l}\text { Mother } \\
\# 3\end{array}$ & $\begin{array}{l}\text { Mother } \\
\# 4\end{array}$ & $\begin{array}{l}\text { Mother } \\
\# 5\end{array}$ & $\begin{array}{l}\text { Mother } \\
\# 6\end{array}$ & $\begin{array}{l}\text { Mother } \\
\# 7\end{array}$ & $\begin{array}{l}\text { Mother } \\
\# 8\end{array}$ & $\begin{array}{l}\text { Mother } \\
\# 9\end{array}$ \\
\hline $\begin{array}{l}\text { Age of } \\
\text { ADHD Child }\end{array}$ & 11 & 9 & 6 & 9 & 10 & 8 & 13 & 13 & 7 \\
\hline $\begin{array}{l}\text { Gender of } \\
\text { ADHD Child }\end{array}$ & $M$ & $\mathrm{M}$ & $\mathrm{M}$ & $M$ & $M$ & $\mathrm{M}$ & $\mathrm{M}$ & $\mathrm{M}$ & $\mathrm{F}$ \\
\hline $\begin{array}{l}\text { Age of } \\
\text { Diagnosis }\end{array}$ & 4 & 6 & 5 & 4 & 6 & 6 & 6 & 8 & 4 \\
\hline $\begin{array}{l}\text { Ages/Genders } \\
\text { of Non- } \\
\text { ADHD } \\
\text { Children } \\
\end{array}$ & $\begin{array}{l}8, \mathrm{M} \\
18 \mathrm{Mo} . \mathrm{F}\end{array}$ & $4, \mathrm{M}$ & N/A & $4, \mathrm{M}$ & $\begin{array}{l}12, \mathrm{M} \\
10, \mathrm{~F}\end{array}$ & $14, \mathrm{~F}$ & $11, \mathrm{~F}$ & $\begin{array}{l}19, \mathrm{~F} \\
15, \mathrm{~F}\end{array}$ & $\begin{array}{l}, \mathrm{M} \\
9, \mathrm{M}\end{array}$ \\
\hline $\begin{array}{l}\text { Highest Level } \\
\text { of Education }\end{array}$ & $\mathrm{BS} / \mathrm{BA}$ & Master's & $\mathrm{BS} / \mathrm{BA}$ & BS/BA & Master's & M.D. & Master's & Master's & Master's \\
\hline $\begin{array}{l}\text { No. Hours } \\
\text { per Week } \\
\text { Work }\end{array}$ & 40 & 40 & 15 & 40 & 35 & 15 & 30 & 5 & 0 \\
\hline
\end{tabular}


Table 2

Demographic Summary

\begin{tabular}{|lc|}
\hline Characteristic & Mean \\
\hline Age of Participants & 42.6 \\
\hline Age of ADHD Children & 9.6 \\
\hline Age of Non-ADHD Children & 9.7 \\
\hline Number of Hours Worked Per Week & 24.4 \\
\hline
\end{tabular}


Table 3

How Mothers Perceive Family Communication when Having an ADHD Child: Three Emergent Themes

\begin{tabular}{|ll|}
\hline Theme & Description/Characterization \\
\hline Relational Management & How mothers manage family relationships \\
& $\begin{array}{l}\text { How mothers manage communication } \\
\text { about ADHD with non-family members }\end{array}$ \\
& \\
\hline Time Management & ADHD child's concept of time \\
& $\begin{array}{l}\text { Less time for other children, spouse, and } \\
\text { self }\end{array}$ \\
\hline Internal and External Support & $\begin{array}{l}\text { Emotional and pragmatic support from } \\
\text { spouse, other family members, and friends } \\
\text { Pragmatic and emotional support from } \\
\text { professionals }\end{array}$ \\
\hline
\end{tabular}




\title{
CURRICULUM VITAE
}

\author{
NAME: $\quad$ Anita Marie Hoag \\ ADDRESS: University of Louisville \\ Department of Communication \\ 310 Strickler Hall \\ Louisville, KY 40292 \\ DOB: $\quad$ Providence, Rhode Island - June 27, 1967 \\ EDUCATION \\ \& TRAINING: $\quad$ B.S., Marketing \\ Northeastern University \\ 1985-90
}

